\title{
Sexual behaviour of university students in south west nigeria
}

\author{
Olaitan, Olukunmi 'Lanre, Ph.D. \\ Department of Human Kinetics and Health Edcuation \\ Universiy of Ilorin, Ilorin, Kwara State, Nigeria \\ Email: lanreolives@yahoo.com
}

\begin{abstract}
The research investigated sexual behavior of University students in south west Nigeria. Four hundred and fifty (450) students selected from south west Nigeria Federal Universities were used for the study. Questionnaires were used for data collection and Chi-square (x) statistical method was employed to analyze data and to test the hypothesis at $\mathrm{a}=0.05$ level of significance. The researcher deduced that all the variables considered had significant influence on the behaviour of students towards sex. The results revealed that the behavior of students towards sex was significantly influenced by their gender, culture, religion and educational status. Based on the outcome of this research, it was recommended that sexual program should be organized in our higher institutions to enlighten students on how to behave, so as to avert the nauseating problem of sexually transmitted infections as well as unwanted pregnancies.
\end{abstract}

Keywords: Abstinence, Prostitution, Sexual Behaviour, Sex Programs, University students, Venereal disease

\section{INTRODUCTION}

Sex is certainly an important part of our lives. We need to look at the world population of more than four billion. Sexual factor is quite strong and its importance of procreation, its surprise that many people think of this on an occasional basis when having sex (Allen, 2005). Sex can be a source of great physical pleasure, it can relieve tensions and anxieties, it can boost self-esteem and make use feel masculine or feminine.

Human behaviour is the collection of behaviour exhibited by human beings and influenced by culture, altitudes, emotions, values, ethics, authority, rapport, hypnosis, persuasion, coercion and or genetics. The behaviour of people falls within a range with some behaviour being common, some usual, some acceptable, and some outside acceptable limits.

Human sexuality has intricate meaning for both individuals and societies. It is a complex mixture of biological response, psychological meaning and societal/cultural overlays (Olaitan, 2009). It is only in recent years that sexuality has been studied in a scientific way by sociologists who seek to report and analyze current sexual behaviour.

Basically, sexuality refers to erotic stimulation. Erotic stimulation refers to what a particular society teaches are the pathways, directly or indirectly, to genital response. The learned aspect of erotic stimulation is obvious. For example, a gynaecological examination is not supposed to be erotic to either the client or the gynaecologist and that husbands and partners therefore should not feel jealous concerning such examinations. If erotic arousal does occur in such a situation, a 
feeling of guilt or qualms will probably arise because there is no cultural support for such a reaction.

Another illustration is that many male dominated cultures assert that for a male to reach orgasm quickly and easily, in a matter of seconds is something to be proud of on the other hand, western society today, contends that such a male is a premature ejaculator and needs therapy to learn to delay organism. So such culture defines the proper way to behave and to think about erotic stimulation. There are cultures where female breasts are not part of the erotic imagery, and there are cultures where obese or very thin individuals are thought to be sexually attractive. Some cultures stress only heterosexual preferences and others permit homosexual eroticism as well.

So, it is clear that the specific ways in which we think, feel, and behave concerning erotic stimulation are socially learned. It is true that without the ability to reach orgasm and without nerve endings to yield pleasure none of these sexual customs would exist. But it is also apparent that the specific way we become erotically stimulated is learned, because the biological factors are the same in virtually all societies but the customs still vary considerably.

Human sexual behaviour or different human sexual practices encompass wide range of activities such as the search for a partner or partners, interactions between individuals, physical or emotional intimacy, and sexual contact.

Some cultures will find only sexual contact within marriage acceptable, however, extra martial sexual activity still takes place. Unprotected sex may result in unwanted pregnancy or sexually transmitted diseases. In some areas, sexual abuse of individuals is prohibited by law and considered against the norms of society. There are two aspects of human sexual behaviour which are cultural and social norms and rules.

Roger in his investigation conducted among students who had undertaken a course on human sexuality revealed that majority of them felt that sexual behaviour will make them to satisfy their emotional needs (Rofer, 2004). Many youth viewed sex programme as a delicate issue and should be left for later years while they prefer the company of opposite sex and play together, such play encourages copulation (Senge, 2003).

Recent studies such as, the youth and sex, education have indicated positively the being that sexual behaviour starts as early as a child begins to grow up to the level of asking questions about sexuality (Conwell \& Jacobson, 2007). This is good development, therefore parents and teachers should be aware of their role in educating their children/students on sex before the start mixing with their friends (peer group) who may want to or corrupt them.

\section{Culture}

Culture is considered as the norms, values, art, belief, moral, custom, knowledge, socio-cultural values, historical heritage of a group, community, settlement, region or a nation which can be identified in them and be of them at any point in time or place.

Culture is everywhere which is socially learned and shared by the members of a society. Culture is defined as practices embarrassing social-political values, socio altitudes ideas, artistic, scientific and historical heritage (Paul, 2003).

Culture is the hereditary beliefs, values, taboos and historical heritage that were passed down in families and clans from one generation to another. In other part of the world, sexuality is treated as a natural part of life and death with rather 
candidly. Some of those western countries treated the issue of sexuality as a way of life and they see nothing wrong in the behaviour of their youth towards sex.

Also, among the inhabitants of West African countries, living arrangement and religious beliefs all promote extreme hostility between men and women, which makes women taught to avoid intercourse because it may cause wrinkling, fussy thinking, stunt growth or loss of hair (Gagnon, 2003).

In Nigeria, because of our subcultures with heterogeneous societies having different views of sexuality, some cultures are less restrictive, some place restriction on it until the time of marriage. For example in Ondo town, Nigeria, it is compulsory for every female to partake in the obintun festival as a virgin, or else, she would not be able to bear children when she gets married, while in some part in Igbo land, they train their children to be sexually active and how to entice opposite sex.

\section{Education}

Education is borrowed from the Latin words educere meaning a movement from ignorance to knowledge, from foolishness to wisdom, from darkness to light.

Education is what should start from him and such education is referred to as informal education. Formal takes place in classroom (Remi, 2000). Education enables us to know the world better and therefore understand it better. Education is the development of intellectual abilities, skills and attitudes all which form our disposition to action in life generally. An educated person would react to many life situation more positively than persons that have not heard or benefited from education. No wonder that plate declared that knowledge was virtue and that ignorance was the root of all vices (Omolaabi, 2004).

Education helps in shaping our sexual idea and perhaps influence general attitude towards educating children on sex issues. Educated parents were more in support of enlighten their children on sex matters than illiterates ones. Generally, educated students develop a positive sexual awareness because of the positive attitude towards sex programs than the illiterate ones who develop a negative attitude towards sex education due to lack of formal education and informal education (Ewuzie, 2003).

\section{Gender}

Sex of the body is determined at birth. The moment a baby is born it is easier to know whether the baby is a boy or girl through the genital organ of the baby, a child's masculine or feminine behaviour depending on its sex, has two components. The first is its gender role which is the way a person behaves to others to demonstrate whether he or she is a male of female (Durojaiye, 2002). The second is the person's own awareness that he or she is a male or female referred to as gender-identity. Parents behave differently towards their male and female children. The daughters are often described by both parents as beautiful, pretty while the sons are referred to as firm large, featured, well coordinated, alert, strong and hard. They were sometimes referred to as "juniors" (Eheazu, 2004).

There are significant sources of information about conceptions, menstruation, abortion and intercourse. Since parent are always out of the home for their daily bread, parents always find it difficult to sit down and teach them knowledge of sex but each time they have the cause to learn about it, they insist discipline when they are aware of any act of immoral or indecent sexual behaviours of their offspring (Spanier, 2008).

\section{Religion}

Religion could be defined as a link between human beings and their creator who people have faith in his existence. Religion is from a Latin word Relegree (to unite or to link) and Religion (relationship). 
Religion is a fixed relationship between the human self and some non-human entity, the sacred, the supernatural, the self existence, the absolute or simply, God (Bouguest, 2001). The family determines the child's religion out look, religious belief and attitude they want him or her to hold on to. They enforce and regulate their children's attitude to church, mosque or shrine attendance for spiritual upliftment and blessing.

However, some significant religions in this part of the world are Christianity, Islam and traditional believers, particularly Christian and Muslim believed that sexual pleasure is sinful before marriage, homosexuality, abortion, gay, masturbation are condemned . Virginity is elevated to a virtue and contact between sexes as is strictly limited. Sex is considered as a sin that will keep them away from God.

Many religious faithful, vehemently oppose the sexual behaviour that most youths put on because of their religious believes, their sermon over radio and television always condemn the indecency and moral laxity and obscurity of youths today. However, Catholic Church strongly supports sex but opposes the distribution of contraceptives (Bouguest, 2001).

Human sexual behaviour or different human sexual practices encompass wide range of activities such as the search for a partner or partners, interactions between individuals, physical or emotional intimacy and sexual contact. Some cultures will find only sexual contact within marriage acceptable; however, extra-marital sexual activity still takes place unprotected sex may result in unwanted pregnancy or sexually transmitted diseases. In some areas, sexual abuse of individuals is prohibited by law and considered against the norms of society.

Historically, in Nigeria sexual behaviour begins right from the childhood, when they are about to reach a year old. They begin and prefer to go for opposite sex. For example, when a lady ask a female baby to come she will not allow her but if it is a male she will allow him with smiles, the same thing applicable to male baby that prefer a lady for a boy like him.

When they reach puberty/adolescent stage which is a peculiar and important stage in human life course, it is a stage of in between because it occurs between the childhood and adulthood stage. This stage is between twelve plus and twenty-one, it is a stage when individual develops the primary and secondary sex characteristics. In females, they develop round hips, armpit hair, hairs from the private part, thin voice, they start menstrual period, breast start shooting out and taking shapes. In males, they start developing guttural voice, road chest, hairs from the private parts. It is the stage that individual develops great affinity to opposite sex. This is what led them to the attitude they put on in institutions because they have been used to the company of opposite sex and the affinity for opposite sex is not properly challenged.

Some feel that it is the parent's responsibility, some studies such as Bolton, shows that when parents are the source of their children's education (that is, providing factual information) the children tend to follow traditional norms in moral behaviour (Bolton, 2006, Lewis, 2003). Surveys have consistently revealed however, that fewer than 10 percent and often fewer than 5 percent of over 1000 students of a particular institution have ever had a serious discussion with their parents about sex.

The students generally received little information from parents about sex. The students generally received little information from their parents other than a description of intercourse and the fact that it could result to pregnancy. Immediately, they tried it and discovered that pregnancy does not occur, they believed that there parents are lying to them and continue with it whereby, they dress the way they like in order to entice male so that they can satisfy there emotional needs. 
The youth had been denied of educative information by institutions from time to time. Likewise, cultures from time immemorial have made adults attitude underscore the youth corrective comprehension of sex and its value, yet these youths watch phonographic films, reading romantic novels and magazine and lower animal perform sex day by day at their doorsteps (Olaitan, 2009). They put all these into experimentation not minding the outcome of there act.

It is hoped that with proper program on sexual related topics, introduction and implementation of dress code in our institutions will go along way in resolving some of the problems relating to sexual behaviour put on by our students in higher institutions especially University of Ilorin's student

\section{Purpose of the Study}

Is to find out the attitude of students towards sex, and to investigate the reasons for the attitude they put on, because some did it as a result of influence of peer group, freedom and money.

Also to determine the level of understanding of our students toward sex, some believed that sex could be practiced or done at anytime, any place, any how or with anybody and without using condom in order to enjoy it the more which is not suppose to be.

Therefore, adequate program on implications of unprotected sex resulting to unwanted pregnancy which mostly lead to abortion and venereal diseases can change the orientation of our students towards sex and reduce the number of people that engaged in abortion yearly and also, the number of people that contacted venereal diseases.

\section{$\underline{\text { Research Questions }}$}

(1) To what extent does gender influence behaviour of students toward sex?

(2) To what extent does culture influence behaviour of students towards sex in institutions?

(3) To what extent does religious belief of the students influence behaviour of students toward sex in institutions?

(4) To what extent does educational status influence students' behaviour towards sex?

(5) To what extent does attitude of students influence their practices toward sex in institutions?

\section{Research Hypothesis}

(1). Gender will not significantly influence behaviour of students towards sex.

(2). Culture will not significantly influence behaviour of students towards sex in institutions.

(3). Religion of the students will not significantly behaviour of students toward sex in institutions.

(4). Educational status will not significantly influence students' behaviour toward sex in institutions.

(5). Attitude of the students will not significantly influence there practice towards sex in institutions.

\section{Methodology}

A multi-stage sampling method was adopted to select 450 respondents from the undergraduate students of universities in south west Nigeria. Close-ended questionnaires were administered to the respondents find out the behaviour of students toward sex in the six universities. The questionnaire developed by the researcher in a four Likert scale of strongly agree, agree, disagree and strongly disagree was used. The first part of the questionnaire sought for the personal data of the respondents. 
The questionnaire validated and tested for reliability in a similar population before used. The researcher and 12 trained research assistants administered the questionnaire to all the respondents in the five Universities. The subjects were briefed on the purpose of the exercise and enough time was given to complete the questionnaire. All completed questionnaires returned were carefully checked to ensure that they were well filled. Statistical Package of Social Sciences (SPSS) 16.0 was employed to analyse the data, using frequency counts and simple percentages for describing the demographic information and Chi-square statistics was used to test the hypothesis at 0.05 alpha level of significance.

\section{RESULTS AND DISCUSSION}

The questionnaires were distributed between male and female, male had $33.33 \%$ responses while females had $66.67 \%$. The number of students that responded in Unilag was $20 \%$ while UNAAB was $18.7 \%$, UI was $26.6 \%$, OAU $16 \%$ and FUTA 18. $7 \%$. The same table showed that 315 Christians at $(43.3 \%), 216$ respondents of Islam faithful at (48\%) and 39 traditional worshippers at $(8.7 \%)$ participated in the study. In age, however, those below 20 years were $20 \%$ while ages between 21 years 25 years were $65.3 \%$ and 26 years and above were just $14.7 \%$ responded to the questionnaire (see table1).

Table 1: Demographic Data (Sex, institution, religion and age) of respondents in percentages

\begin{tabular}{|c|c|c|c|}
\hline \multicolumn{2}{|r|}{ Variables } & Frequency & Percentage (\%) \\
\hline \multirow[t]{2}{*}{ Sex } & Male & 150 & 33.3 \\
\hline & remaie & 300 & $00 . /$ \\
\hline \multirow{5}{*}{ Institution } & University of Lagos, Akoka, Lagos State (Unilag) & 90 & 20 \\
\hline & University of Agriculture, Abeokuta, Ogun State (UNAAB) & 84 & 18.7 \\
\hline & University of Ibadan, Ibadan, Oyo State (UI) & 120 & 26.6 \\
\hline & Obafemi Awolowo University, Ile-Ife, Osun State (OAU) & 84 & 18.7 \\
\hline & Federal University of Technology, Akure, Ondo State (FUTA) & 72 & 16 \\
\hline \multirow[t]{3}{*}{ Religion } & Christianity & 315 & 43.3 \\
\hline & Islam & 216 & 48 \\
\hline & Traditional & 39 & 8.7 \\
\hline \multirow[t]{3}{*}{ Age } & Below 20 years & 90 & 20 \\
\hline & $21-25$ years & 294 & 65.3 \\
\hline & 26years and above & 66 & 14.7 \\
\hline
\end{tabular}

The results of the analysis were presented in table 2 as shown. In hypothesis 1 , through the analysis of data, the results showed that gender significantly influenced the sexual behaviour of university students in south west Nigeria, because the calculated value of (109.26) is greater than the critical value of (16.92) with degree of freedom of 9 (Table 2), which made the hypothesis to be rejected. Spanier agreed with this finding and said that, parents always find it difficult to sit down and teach them when they were young (Spanier, 2008).

The second hypothesis which states that culture will not significantly influence the behaviour of students towards sex. The result from the data collected revealed that culture have significant influence on the behaviour of students towards sex in Universities in south west Nigeria, because the calculated value (193.34) is greater than the critical value (12.59) with degree of freedom 6 (Table 2), in which the hypothesis was rejected. This finding is supported by Gagnon who found that, among the inhabitants of West-African countries living arrangement and religion beliefs promote extreme hostility between men and women, make her thought to avoid 
intercourse because it may cause wrinkling, fussy, thinking, stunt growth or loss of hair (Gagnon, 2003).

Table 2: Chi-square $\left(\mathrm{X}^{2}\right)$ results on gender, culture, religion and education influence on sexual

\begin{tabular}{|l|l|l|l|l|l|}
\multicolumn{1}{c}{ Dehavoiur } & Calc. $\mathrm{X}^{2}$ & Df & Table Value & Decision on Ho \\
\hline S/No & Variables & 109.26 & 9 & 16.92 & Rejected \\
Ho 1 & Gender vs Sex behavior & 193.34 & 9 & 15.59 & Rejected \\
Ho 2 & Culture vs Sex behaviour & 193.27 & 9 & 16.92 & Rejected \\
Ho 3 & Religion vs Sex behaviour & 75.27 & 6 & 15.59 & Rejected \\
Ho 4 & Education vs Sex behavior & 53.08 & 68 \\
\hline
\end{tabular}

$\mathrm{p} \leq 0.05$

For hypothesis three, data collected revealed that religion significantly influence the behaviour of students towards sex, because the calculated value (75.27) is greater than the critical value (16.92) with the degree of freedom 9 (Table 2), which make the hypothesis to be rejected. This is in line with Bouguest who opined that, Catholic Church strongly supports sex but opposes the distribution of contraceptives (Bouguest, 2001).

In hypothesis four, the result obtained after analysis showed that educational status will significantly influenced the behaviour of university students towards sex, because the calculated value (53.08) is greater than the critical value (12.59) with degree of freedom 6 (Table 2), which make the hypothesis to be rejected. This implies that people should be educated so as to gain knowledge on sexuality and sex education.

\section{Conclusions and recommendations}

In conclusion, the study revealed that certain factors like gender, religion, educational status and culture have influence on the sexual behaviour of university students in south west Nigeria. Also, civilization which has been a tool of socialization significantly influenced the sexual behaviour of university students. Meanwhile, gender of students was seen to have significant influence on the sexual behaviour of University students, in view of the revelation that female students develop keen interest in sexual program because they are at the receiving end of any unusual happenings.

In view of the findings, the following recommendations were made.

1. The students on their part are advised to take proper care of the factual information on sex that are passed to them and avoid using such knowledge wrongly at the expense of their education and lives.

2. The religion bodies should see sex naturally as pure and creative. Various religions organizations are hereby urged to supplement efforts to make our society free from sexual problems by being open minded diachronic sex issues with all sense of responsibility and avoid giving ridiculous meaning of sex.

3. Public program for youths on sexuality should be in mosques, churches, shrines and markets through the use of films, radio and television should be promoted by the sexual, reproductive and family health experts.

4. The government should train and post more sexual, reproductive and family health experts and health counselors to schools to take care of students affective needs.

5. Sexual program should be organized in our higher institutions to enlighten students on how to behave both morally, so as to avert the nauseating problem of sexually transmitted infections as well as unwanted pregnancies. 
6. Parents should also be aware as worthwhile model to their offspring by actually putting into practice what they preach.

\section{APPENDIX \\ Questionnaire on investigation into sexual behaviour of University students (Qiisbus)}

Dear Respondent,

The purpose of this study is to find out the sexual behaviour of university students in south west Nigeria.

I therefore ask for your honest and frank response. Your responses will be strictly confidential.

Sincere responses shall be appreciated.

Thanks.

Yours sincerely,

\section{O. 'Lanre OLAITAN, Ph.D. \\ Reproductive \& Family Health Specialist (Researche) SECTION A: DEMOGRAPHIC DATA}

Instruction: $\quad$ Please, tick ( 1 ) the appropriate column to answer the following Gender: $\quad$ Male ( ) questions.

Institution.

Religion: $\quad$ Christianity ( ), Islam ( ), Traditional ( ).

Age: Below 20 yrs ( ), $21-25$ yrs ( ), 26 yrs and above ( ).

\section{SECTION B: GENERAL INFORMATION ON SEXUAL BEHAVIOUR}

Instruction: Please, tick ( $\bigvee$ ) the appropriate column to respond to the statements below.

\begin{tabular}{|c|c|c|c|c|c|}
\hline $\mathbf{S} / \mathbf{N}$ & Gender and Sexual Behaviour & SA & $\mathbf{A}$ & $\mathbf{D}$ & SD \\
\hline 1. & Female students are more sensitive to sexual related issues than male students. & & & & \\
\hline 2. & Male students prefer unprotected sex than the female students. & & & & \\
\hline 3. & Unwanted pregnancy is as a result of peer group influence. & & & & \\
\hline 4. & I have had sex discussion on with your friend in school before. & & & & \\
\hline \multirow[t]{2}{*}{5.} & Female students are more sexually moved when touched than male students. & & & & \\
\hline & Culture and Sexual Behaviour & & & & \\
\hline 6. & My culture supports the organization of sex programmes in tertiary institutions. & & & & \\
\hline 7. & I believed that civilization has affected the altitude of students towards sex practices in tertiary institutions. & & & & \\
\hline \multirow[t]{2}{*}{8.} & My culture gives room for pre-marital sex. & & & & \\
\hline & Religion and Sexual Behaviour & & & & \\
\hline 9. & My religion supports the organization of sex programmes in tertiary institution. & & & & \\
\hline 10. & Religion of students affects their altitude towards sexually related issues. & & & & \\
\hline 11. & There is likelihood of sexual activity reduced among students in religious schools. & & & & \\
\hline \multirow[t]{2}{*}{12.} & My religion gives room for student participation during sex related discussion. & & & & \\
\hline & Education Attainment & & & & \\
\hline 13. & Individual educational background influences his/her sexual behaviour. & & & & \\
\hline 14. & The illiterates commit more sexual crimes than the literate ones. & & & & \\
\hline 15. & I think sex programmes should be in the school activities. & & & & \\
\hline
\end{tabular}




\section{ACKNOWLEDGEMENTS}

I am grateful for the valuable comments and suggestions of Professor O.G Oshodin, the Vice -Chancellor, University of Benin, Edo State, Nigeria, Professor D. B. Parakoyi of the Department of Epidemiology and Community Health, University of Ilorin, Kwara State, Nigeria, Professor O.O. Obiyemi, Director of Institute of Education, University of Ilorin, Kwara State and Professor E.A. Ogunsakin, the, Head of Department, Human Kinetics and health education, University of Ilorin, Kwara State, Nigeria. Also to my research assistants who are Post Graduate students in both Public Health, and Health Education in the university of Ilorin for taking pains to go round the selected universities for the distribution and collection of questionnaires.

\section{REFERENCES}

Allen, D.M.A. (2005). Young male prostitutes: a psychosocial study, Archives of Sexual Behaviour 4(2): 394-426.

Bolton, F.G. (2006). The pregnant adolescent: problems of premature parenthood. Chicago: Beverly Hills, C.A. Sage.

Bouguest, A.C. (2001). Comparative religion middle sex, New York: Penguim Books United States.

Conwell, E. R. and Jacobson, L. (2007). The adult and sex education, American Journal of Public Health, 619: 1840-1845.

Durojaiye, M.O. (2002). Sex differences in adolescent character process in bardwin, New York.: Haper Publications Page:

Eheazu, B. A. (2004). Society Schools and Sex Programs. Paper presented at Conference in Sex Education for Nigeria Youth. Cross River State University, Uyo. Unpublished Paper.

Ewuzie, C.N, (2003). The Need for Sex Programmes in Our Institutions. A Seminar on Nigeria Youths, Uyo, Cross-Rives Unpublished Paper.

Gagnon, J. H. (2003). Human sexualities. New York: Glenview, IL, Scott, Foreman.

Lewis, R.A. (2003). Parents and peers: socialization agent in the coital behaviour of young adult. The Journal of Sex Research. 9: 156 - 170.

Paul, G, (2003). Sex Programmes Today World Health Organisation Magazine pp.1-11.

Olaitan, O.L, (2009). HIV/AIDS' knowledge and condom usage as preventive measure among university students in South West Nigeria. Egyptian Academic Journal of Biological Science, 1(1): 1-5

Omolabi, R. (2004). A Practical Approach to Philosophy of Education, University Press Limited Ibadan.

Remi B, (2000). Sociological Foundation of Nigeria Education: Lagos: Univ. Press Ltd.

Rogers, R.S. (2004). Sex Education,London: Alder Press Oxford. England.

Senge, W, 2003: Adult Views to Sex Programmes: Health Education of Marriage and the Family. 41(2): $42-48$.

Spanier, G. B. (2008). Sexual socialization and pre-marital sexual behaviours. an empirical investigation of the impact of formal and informal education. Published in New York. 